\title{
Admitting Mentally Ill Mothers with their Babies into Psychiatric Hospitals
}

\begin{abstract}
R. Kumar, Reader in Psychosomatic Medicine, Institute of Psychiatry and Honorary Consultant, Bethlem Royal and Maudsley Hospitals, London; E. S. Meltzer, Consultant Psychiatrist, Warley Hospital, Brentwood, Essex, formerly Senior Registrar, Bethlem Royal and Maudsley Hospitals; Rosalind HePplewhIre, formerly Assistant House Governor, Bethlem Royal and Maudsley Hospitals; and A. D. Stzvenson, Operational Services Manager, BUPA Hospitals Ltd., London, formerly Assistant House Governor, Bethlem Royal and Maudsley Hospitals
\end{abstract}

The clinical management of a mother who has a severe puerperal mental disorder is complicated by the fact that her baby is not ill and does not need to be in hospitalespecially a psychiatric one. On the other hand, separating babies from their mothers can have adverse effects upon their relationship and upon the psychological development of the infant, although much depends upon the timing, nature and duration of the separation as well as on the quality and stability of the family background. ${ }^{1.2}$

Admission of mother and baby together into a psychiatric hospital has become increasingly common in Britain following the reports of successful in-patient treatment of mothers with neurotic difficulties at the Cassel Hospital ${ }^{3}$ and then of schizophrenic mothers who were admitted to hospital with their babies." 'Mother and baby' units have since been established in a few places in Britain and abroad, ${ }^{5}$ but the demands on facilities, staff numbers and skills are considerable and the units are expensive to run. In parts of the country where special units are not available and faced with the dilemma of possible unnecessary separation of a mother and her baby, hospital staff may try to meet the clinical need from within existing resources. This survey attempted to find out by questionnaire how such needs were being met in the South East Thames Health Region, and to try to relate information about the services with an enquiry ${ }^{6}$ into the clinical condition of the mothers who were using those services.

The South East Thames Region covers a large area of Southern England and it has a total population of over 3.5 million people. The birth rate in 1979 and 1980, the two years upon which the clinical part of this study focused, was 42,528 and 44,255 i.e. 12.5 and 12.9 live births per thousand population. It has been estimated ${ }^{7.8}$ that between one and two in every thousand mothers requires admission to mental hospital with a post-partum psychosis. Thus, in the part of England covered by the SE Thames Regional Health Authority (SETRHA), 40-80 mothers with young infants and with severe mental illnesses may need in-patient psychiatric treatment each year. Only one psychiatric hospital in the region was officially listed (DHSS, 1976) ${ }^{9}$ as having four places which were designated for the use of mothers and babies and this figure has not been updated since then.

\section{Methods}

The hospitals and units surveyed in 1979 and 1981

The same method was used in the original survey in 1979 and in the follow-up enquiry two years later. The enquiry was not restricted to mental hospitals and units because we hoped to find out more about the paths that existed between, for example, obstetric hospitals and units and other health service facilities in which mentally ill mothers might receive in-patient or day-patient care. Accordingly, questionnaires were sent to 75 out of the total 155 hospitals and units in the region, which could conceivably have some role in the care of such mothers and their babies. A $100 \%$ return rate was ensured by telephoning the administrators of those hospitals which had not returned their questionnaires.

The Bethlem Royal and Maudsley Hospitals have their own governing authority and may admit patients from far afield. Nevertheless, these hospitals are located in the SE Thames Region and do also serve a local population. Their data are therefore included in this Regional survey.

\section{Questionnaire}

In the autumn of 1979, a questionnaire was sent to the senior administrators of each of the $\mathbf{7 5}$ hospitals asking whether they had any psychiatric facilities set aside for mothers and babies. If none, how did their hospitals deal with mothers requiring admission? If fäcilities were available, were these separate or in a general ward and how many 'beds' and 'cots' (i.e. places) were provided? Could they accommodate fathers, other children or relatives? Did mothers have to share normal ward facilities, e.g. bathrooms, toilets, dining rooms, day rooms, or did they have sole use? Was there a single consultant in charge of the facilities and what extra staff establishment was there, e.g. medical, nursing, psychologists, social workers, OT? Up until what age were babies admitted with their mothers, and how many such admissions had been recorded in the years 1975-8? Finally, were there any instances of day-patient care without in-patient admission? Two years later, in autumn 1981, the same questionnaire was updated, with enquiries about any changes in facilities since 1979 and admissions during the years $1979-80$. The responses 
showed that there were 12 hospitals in the region which admitted mothers and babies and they were visited in 1982-3 by one or both investigators concerned with the clinical part of this study ${ }^{6}$ thus giving us an opportunity to see the facilities.

\section{Results and discussion}

Facilities

Table I lists the 12 hospitals which had admitted babies with their mentally ill mothers at some time in the years 1979-1980; the number of places and the facilities provided by each hospital are also shown. Developments since 1980 , such as the setting up of a specialised mother and baby unit at the Bethlem Royal Hospital are also listed in Table I.

\section{Staffing and Management Policies $1979-80$}

All the hospitals were making do within their regular nursing staff complements and only at Joyce Green was there nominally an 'extra' nurse who was regarded as being specially responsible for the mothers and babies. There were no nursery nurses at any of the hospitals and access to other services, e.g. social services, psychology, OT, was the same as for other patients. Medical responsibility was shared; the consultant who admitted the patient usually remained in charge. It was possible, in theory, for up to four consultants to be involved at any one time in some hospitals, but referrals often gravitated to individual psychiatrists who were known to have a special interest in the care of mothers and babies.

TABLE I

Summary of facilities for mothers and babies in the SE Thames Region

\begin{tabular}{|c|c|c|c|c|c|c|}
\hline \multirow[t]{2}{*}{ Hospital } & \multirow{2}{*}{$\begin{array}{l}\text { Max. No. of } \\
\text { Places In } \\
1980\end{array}$} & \multirow{2}{*}{$\begin{array}{l}\text { Location } \\
\text { of } \\
\text { Cots }\end{array}$} & \multirow{2}{*}{$\begin{array}{l}\text { Max. Age of } \\
\text { Babies } \\
\text { (Months) }\end{array}$} & \multirow[t]{2}{*}{ Comments } & \multicolumn{2}{|c|}{ Admissions } \\
\hline & & & & & 1979 & 1980 \\
\hline Hellingly & 4 & $\begin{array}{l}\text { side rooms or } \\
\text { nursery }\end{array}$ & 12 & $\begin{array}{l}\text { Two more places }+ \\
\text { nursery added in } 1981\end{array}$ & 10 & 8 \\
\hline St Augustine's & 2 & nursery & 18 & $\begin{array}{l}\text { Closed } 1977 \text {-reopened } \\
\text { in } 1980 \text { separate } \\
\text { bathroom and kitchen }\end{array}$ & 0 & 13 \\
\hline Oakwood & 1 & side room & 12 & $\begin{array}{l}\text { Closed 1980-nursing } \\
\text { shortage. Upgrading } \\
\text { under discussion }\end{array}$ & 4 & 1 \\
\hline $\begin{array}{l}\text { All Saints, } \\
\text { Chatham }\end{array}$ & - & pediatric ward & 6 & & - & - \\
\hline Joyce Green & 4 & $\begin{array}{l}\text { in unit with } \\
\text { mother }\end{array}$ & 9 & $\begin{array}{l}\text { Separate nursery/play } \\
\text { area, day room, dining } \\
\text { area, laundry, toilet, } \\
\text { bath }\end{array}$ & 11 & 17 \\
\hline Greenwich & 2 & nursery & 12 & & 15 & 19 \\
\hline $\begin{array}{l}\text { South Western, } \\
\text { (St. Thomas's) }\end{array}$ & 2 & side rooms & 24 & & 6 & 5 \\
\hline Guy's & 1 & side room & 6 & & 1 & 1 \\
\hline $\begin{array}{l}\text { St Giles } \\
\text { (King's) }\end{array}$ & 4 & side room & 12 & $\begin{array}{l}\text { Transferred } 1983 \text { to } \\
\text { Dulwich North. No } \\
\text { facilities for babies }\end{array}$ & 2 & 5 \\
\hline $\begin{array}{l}\text { Bethlem/ } \\
\text { Maudsley }\end{array}$ & 3 & nursery & 12 & $\begin{array}{l}\text { Closed 1980, reopened } \\
1982 \text { with } 8 \text { places, } \\
\text { separate facilities and } \\
\text { staff team including } \\
\text { nursery nurses }\end{array}$ & 12 & 3 \\
\hline Farnborough & 2 & $\begin{array}{l}\text { side room or } \\
\text { nursery }\end{array}$ & 12 & & 3 & 4 \\
\hline Cane Hill & 1 & side room & 12 & & 2 & 0 \\
\hline & 26 & & Totals & & 66 & 76 \\
\hline
\end{tabular}


In three hospitals, the babies routinely stayed in separate nurseries and the mothers' access was regulated by staff if this was thought necessary. In the other hospitals, the mothers and babies were put up together in single rooms with cots added. If the mother was too disturbed, then babies were either nursed in separate rooms (side rooms, utility rooms etc. turned into 'nurseries') or, alternatively, they remained at home with relatives or friends, or were fostered through the agency of social services. The general policy, therefore, was to maintain contact between mother and baby, but hospitals put this into effect in different ways. In two hospitals, access was always supervised by staff, and this strict regime had been imposed following incidents in which babies had been harmed. In other hospitals the approach was more flexible, often beginning with supervised access and culminating in 'rooming together' as the mother's condition improved. Our impression, however, was that the amount of access was more often dictated by the availability of nursing staff than by formal policy.

\section{Status of babies}

There is some doubt about the true status of the babies while residing with their mothers in psychiatric units and hospitals. Several hospitals considered them to be patients and medical responsibility for their care was assigned either to pediatricians when the facility was in a district general hospital, or to psychiatrists if the mothers and babies were in a mental hospital. In one hospital, babies were considered to be guests and their health care became the responsibility of a local general practitioner with whom they were registered for the duration of their mothers' admission.

\section{Age of babies}

Table I lists the ages up to which hospitals were prepared to admit babies. Our clinical enquiry ${ }^{6}$ was restricted to 142 mothers with babies aged less than a year at the time of admission, but we noted that only eight babies above the age of 12 months were admitted with their mothers to any of these hospitals during 1979-80. Below a year, the peak time of admission was when the babies were two weeks old and $70 \%$ of admissions had occurred by six weeks; the remainder were mostly spread up to six months. There were a few readmissions after six months, but only $8 \%$ of the new admissions occurred between six and 12 months post-partum.

\section{Numbers of admissions, their sources, their duration and 'bed occupancy'}

The numbers of admissions by individual hospitals during the two years $1979-80$ are shown in Table I; the data for 1975-8 were incomplete and are not described here. Only five of the 142 mothers resided outside the SE Thames Region, three went to the Bethlem Royal and two to Joyce Green which, until 1982, provided the only specialised facility. As a consequence of changes in the official system (ICD-9) for classifying and notifying puerperal mental disorder, we were unable to discover how many mothers and babies living in the South East went to hospitals outside the region, nor how many mothers were admitted without their babies. ${ }^{6}$ For the same reason it was not possible to identify relevant admissions to All Saints Hospital, because mothers and babies were admitted to different wards and their records were kept separately.

The rates of admission by individual hospitals varied between 1 and 9.5 per notional place per year. The duration of admission was related to the nature of the mother's condition; for example, women with depressive disorders stayed in hospital with their infants for a mean of about four weeks, whereas those with manic, schizophrenic and schizoaffective illnesses remained in hospital on average twice as long. Women with other children at home had briefer stays in hospital. ${ }^{6}$

Simple measures of adult bed occupancy are likely to be misleading in this context because the beds did not necessarily lie vacant when they were not being used by mothers. Overall the sample $(n=142)$ and all the beds $(n=26)$ each place was occupied by a mother for an average of 14 weeks each year. Thus, when not in use, a nursery could be closed off or turned back into a utility room and the adult bed used for a general patient. Because no extra staff had been employed, questions about what to do with a temporarily unemployed nursery nurse, for example, did not arise. The quality of the service may, however, vary considerably depending upon the availability of special resources and staff ${ }^{3}$ and the demands on staff that are made by a mentally ill mother and her baby when nursed together, are much more than the sum of the parts.

\section{Use of community services and resources}

Day hospital attendance was rarely used as an alternative to in-patient care and only three hospitals regularly called upon community psychiatric nurses to see patients at home. The severity of the mother's condition may dictate the extent to which she is managed outside hospital. Oates ${ }^{10}$ has recently described more flexible ways of deploying clinical services for mothers with psychotic illnesses, by using domiciliary care as an integral and major part of a service which reaches out from hospital. Community care might have been possible for at least a third of the patients we surveyed ${ }^{6}$ in whom the primary diagnosis was that of nonpsychotic or relatively minor psychiatric disorder. Our case note data were not detailed enough to examine the contribution of social factors as causes of admission, but there were very few 'cold' admissions-i.e. referrals from social services to assess 'mothering skills', motivation or risks from the mother of causing injury to the child. Mother and baby facilities in this region were hardly ever used in this way.

\section{Conclusions}

This survey shows how the services in one health region have evolved piecemeal to meet a particular clinical need without incurring substantial capital costs and virtually no demands on recurring revenue. This has proved possible 
because the load has been spread across a number of psychiatric hospitals and units in teaching and district general hospitals that are scattered across the region. An obvious advantage of a decentralised service is the relative proximity of the hospital to the patient's home. One disadvantage of a thinly spread service is an inevitable limitation of the types of specialised in-patient care and treatments that can be offered to mothers and their families. Although large units are costly, they do also provide an essential platform for research into puerperal mental illness and its consequences.

The great majority of mothers want to be with their babies and to look after them if they can, in spite, quite often, of very severe mental and behavioural disorganisation. Most such women are first-time mothers (two-thirds of our sample were primiparae) and the amount and quality of the interaction between mother and baby may have enduring consequences for both of them. Prolonged admissions in which infants are inevitably cared for by many pairs of hands may create their own problems. The circumstances in which the benefits of joint admissions of mothers and babies outweigh the possible disadvantages therefore need to be clarified. The lack of research into these kinds of questions is striking. In the case of multiparae, who made up a third of our sample, admissions effectively meant separation from their other, older children; their short stays in hospital presumably reflected a greater pressure to return home, but there was no evidence that illnesses in the multiparae were in any way less severe than in primiparae.

Most facilities are working in isolation from each other and there are no accurate registers of the services that are available. " Post-partum psychotic illnesses usually present as acute psychiatric emergencies within a week or two of delivery. Liaison between obstetricians and general practitioners and psychiatric and social services could be greatly facilitated by the availability of such registers. At present there are few opportunities for comparing notes, discussing operational policies at a local or a regional level, or for carrying out research, e.g. into outcome, following differing treatments and methods of clinical management. It is our hope that by documenting what is happening in one region, we and our colleagues have made a start in this direction.

\section{Recommendations}

(1) Compilation of regional and national registers of in-patient facilities for mentally ill mothers with young infants.

(2) Clarification of the status of babies who are in hospital with their mothers.

(3) Planning and coordination of services at a regional level to link day and community care with local in-patient facilities and, where possible, with large, specialist mother and baby units.

(4) Studies of the clinical efficacy and cost-effectiveness of different forms of services for mothers and babies and the promotion of research into prevention and treatment of severe postnatal mental illness.
ACKNOWLEDGEMENTS

We should like to thank all our colleagues, administrators, nurses and medical staff in the $\mathbf{7 5}$ hospitals in the Region for their patience and cooperation. We are particularly grateful to the staff of the hospitals with mother and baby facilities for the care with which they replied to our questions.

\section{REFERENCES}

'Herbert, M., Sluckin, W. S. \& Sluckin, A. S. (1982) Mother-to-infant 'bonding'. Journal of Child Psychology and Psychiatry, 23, 205-222.

${ }^{2}$ RUTTER, M. (1971) Parent-child separation: psychological effects on the children. Journal of Child Psychology and Psychiatry, 12, 233-260.

${ }^{3}$ Man, T. F. (1958) Mothers with children in a psychiatric hospital. Lancet, it, 845-847.

${ }^{4 B}$ Aker, A. A., Morison, M., GAME, J. A. \& Thorpe, J. G. (1961) Admitting schizophrenic mothers with their babies: Lancet, $\mathrm{H}$, 237-239.

${ }^{5}$ Margison, F. \& Brockington, I. F. (1982) Psychiatric mothers and baby units. In Motherhood and Mental Illness. London: Academic Press, pp 223-238.

6Meltzer, E. S. \& Kumar, R. (1985) Puerperal mental illness, clinical features and classification: a study of 142 'mother and baby' admissions. British Journal of Psychiatry, 147, 647-654.

'Thomas, C. L. \& Gordon, J. E. (1959). Psychosis after childbirth: ecological aspects of a single impact stress. American Journal of Medical Science, 238, 363-388.

${ }^{8}$ Granville-Grossman, K. (1971) Post-partum mental disorders. In Recent Advances in Clinical Psychiatry. London: Churchill.

'DePartment of Health \& Social Securtty (1980) Facilities and Services of Mental Illness and Mental Handicap Hospitals and Units in General Hospitals-1976. London: HMSO.

${ }^{10}$ Ontes, M. 'Alternatives to admission'. (1984) Paper read at a Symposium on the Psychiatry of Motherhood, South Staffordshire Medical Centre, Wolverhampton UK.

"ShawCross, C. R. \& McRAE, Y. (1986) Mother and baby facilities in England. Bulletin of the Royal College of Psychiatrists, 10, so-s1.

\section{Apology}

We very much regret the recent delays in delivery of the Journal and the Bulletin, which have been due to printing difficulties. Every effort is being made to ensure that future issues reach readers on time.

Hugh Freeman

Editor

The British Journal of Psychiatry

Programmes for the Study Tour to Spain to be held 16-22 October 1986 in Madrid and Granada and abstract forms for poster presentations at this meeting are available from Deborah Hart, Assistant Secretary. Members are requested to contact the College as soon as possible. 